\title{
Reassessing Inclusion Of Environmental Justice In The EIS Process: A GIS-Based Study Of Lambert-St. Louis International Airport
}

\author{
Michael Most, Charley Rodriguez, and Michael Burgener \\ Southern Illinois University Carbondale
}

\begin{abstract}
Populations identified as poor or minority under federal guidelines are protected against discriminatory actions which may result from a myriad of activities, including transportation system capacity enhancements: those infrastructure construction projects intended to improve or expand routes and facilities. The outcomes of environmental justice investigations, and, consequently, the conclusions based on the results of such studies, are critically dependent upon the analytical strategy to be applied in deriving statistical outcomes and the spatial resolution of the research design as dictated by the researcher's choice of reference unit and the selection of a particular areal analysis methodology. This paper investigates the potentially confounding effects of certain research strategies, as applied to an analysis of a large midwestern airport and examines the implications of the outcomes for capacity enhancements within the context of the air transportation system.
\end{abstract}

\section{INTRODUCTION}

$\begin{array}{ccc} & \text { On February 11, 1994, President Clinton } \\ \text { signed } & \text { Executive Order EO12898, }\end{array}$ "Environmental Justice in Min ority Populations," to ensure, as its title implies, equity and justice for "protected populations"those groups identified under federal guidelines as being indigent or minority. Definitions of environmental justice (EJ) vary considerably, often depending on the political goals or aspirations of the individual(s) or entity providing the semantic context (Liu, 2001). The United States Environmental Protection Agency (USEPA) Office of Environmental Justice (1999) defines EJ as:

The fair treatment and meaningful involvement of all people regardless of race, color, national origin, or income with respect to the development, implementation, and enforcement of environmental laws, regulations and policies. Fair treatment means that no group of people, including racial, ethnic or socioeconomic groups, should bear a disproportionate share of the negative environmental consequences resulting from industrial, municipal, and commercial operations or the execution of federal, state, local, and tribal programs and policies.(p. 6) The United States Department of Transportation, Federal Aviation Administration (USDOT, FAA) (2000) defines environmental justice in the following way:
Environmental justice is the fair treatment and meaningful involvement of people of all races, cultures, and incomes, with respect to the development, implementation, and enforcement of environmental laws, regulations, and policies. Ensuring "fair treatment" of all people does not mean that risks should be merely shifted from one population to another; rather, the goal of environmental justice is for Federal decisionmakers to identify impacts that are disproportionately high and adverse, and identify alternatives that will avoid or mitigate these impacts. (p. 2)

As a result of EO12898, Federal agencies, administrations, departments, and bureaus have become deeply involved in monitoring potential environmental impacts on populations defined by regulatory criteria as being predominately minority or poor in composition and consequently protected under the broad aegis of the Federal Government. Ensuring environmental justice is a priority for the Environmental Protection Agency (EPA) (Liu, 2001). Both the Federal Aviation Administration (FAA) (FAA, 2000; USDOT, FAA Southern Region, 2000), and its parent organization, the United States Department of Transportation (DOT) (Forkenbrock \& Schweitzer, 1999; Steinberg, 2000), among other agencies and offices within the Federal Government, have implemented environmental equity (EE) policies, procedures and guidelines 
and assigned staff to police discrimination cases and resolve environmental justice disputes (Forkenbrock \& Schweitzer, 1999). As a consequence, noise pollution, among other impacts, must be evaluated within the context of environmental justice criteria and considered in performing an environmental assessment (EA) or included as a component of any airport environmental impact statement (EIS).

Noise is the paramount environmental concern at airports (Ott, 2001). Airport environmental equity issues related to noise arise where increasing numbers of flight operations or capacity enhancements (e.g., runway constructions or extensions) result in elevated levels of sound energy (actual or anticipated) which are perceived to disproportionately affect "protected" populations - those identified as predominantly indigent or minority in composition when compared to a larger reference group. Historically, noise related environmental impacts have represented a significant impediment to the realization of airport capacity enhancements.

In a period approaching 30 years, only 4 new major airports have been built in the United States: Dallas/Fort Worth, Southwest Regional, Denver International and Austin Bergstrom (McNerney, 1995). "Only six new runways were built during the 1990s, when airline departures increased by more than $25 \%$ to 8.6 million a year" (Alonso-Zaldivar, 2001, p. 1). "'Only concrete investments are going to truly make the system more efficient and responsive to . . . demands,' said John Carr, president of the National Air Traffic Controllers Association. 'By concrete, I mean back the trucks up and start pouring us some more runways-please" (Salant, 2001, p. 2).

However, it's not just a matter of backing cement trucks to the forms and "pouring some runways." It is generally accepted that it takes 10 to 15 years from conception to completion of a runway at nearly any major airport (Alonoso-Zaldivar, 2001; Torriero \& Zajac, 2001). The greatest portion of this time is spent in executing and assuring compliance with " . . . 28 federal laws, 12 executive orders, hundreds of lesser federal regulations and dozens of local rules and ordinances ... "
(Torriero \& Zajac, 2001, p. 1). An FAA study found that approval of just the environmental impact statement for runway construction in a metropolitan area required an average of 4.5 years. (This came as a complete surprise to the agency who had " . . . been telling customers it normally ... [took] 2 to $2 \frac{1}{2} 2$ years") (USDOT, FAA Southern Region 1999, p. 1). The inclusion of environmental justice evaluations as part of the EIS process has the potential to increase both costs and construction time for any airport capacity enhancement. Therefore, it is extremely important that, with respect to environmental justice issues, the environmental impact statement assessment is based upon unflawed, empirically derived criteria. The authors will subsequently demonstrate that, in the particular of elevated noise levels in areas surrounding an airport, this is not necessarily the case.

\section{SOME PRELIMINARIES REGARDING ENVIRONMENTAL EQUITY}

Depending on one's point of view, the concept of environmental equity or environmental justice may be either sublime or anathematical; noble or odious; ameliorative or pernicious-if you are the Reverend Jessie Jackson or Professor Robert Bullard, environmental justice is the Holy Grail; if an airport manager, a Procrustean bed. The marriage of the two terms, environment and justice, is certain to strike an empathetic chord with the majority of Americans who will recognize these as two positive concepts, desirable, even essential. Critics counter that the rationale in linking these two words, each with an inherently positive association, is that such a joining will engender a sort of synergy wherein the dyad carries greater force than that provided by the connotative sum of the individual words. Thus, defacto acceptance is ensured wherever the phrase may be used (Perhac, 2000). To better understand this ambivalent dichotomy, capable of producing intense emotions in stakeholders at all levels, an accounting of the events leading to the current state of environmental justice (and associated regulations) may be edifying. 
But first permit the brief justification of a convention to be observed throughout the remainder of this paper. While the concept of environmental equity has been proffered and brandished under several labels (Liu, 2001; Pellow, 2000; Ringquist \& Clark, 1999) (e.g., environmental racism, environmental injustice, environmental inequity, environmental discrimination, ecojustice), the best known among these is environmental justice. Identifying and associating this concept through a variety of terms, which are given to nuances in meanings and definitions of broader or narrower scopes, produces significant problems in the literature (Pellow, 2000; Ringquist \& Clark, 1999). "Different terms reflect different political imperatives and symbolize various icons for mobilizing mass support for public policy objectives ... [E]nvironmental equity is relatively technical and unprovocative . . . Environmental racism is 'provocative and evocative-an excellent media tool' for mobilizing the attention of people of color" (Liu, 2001, p.13). Environmental justice became the term of choice during the Clinton presidency (Liu, 2001.)

"Environmental justice is one of the most loaded expressions in the political lexicon" (Steinberg, 2000, p. 82). It carries the connotation of an entitlement, of a group or individual wronged, of a debt owed. However, as we shall see, the literature does not necessarily support this assertion. Implicit in the term, environmental justice, is the perpetration of a harmful act upon which justice must be visited to reconcile the wrongdoing. It is a captious phrase. The terms environmental injustice, environmental discrimination, environmental inequity and environmental racism are equally objectionable on similar grounds, connotatively implying guilt without due process. On the other hand, the phrase, environmental equity, implies fairness, and given the current Zeitgeist, wherein hypersensitivity to the suggestive nature of connotative implications abound, we, the authors, believe this latter is the best choice from among the alternatives. Therefore, with the exception of phrases quoted from other sources, environmental equity will be the preferred term throughout the remainder of this paper.

\section{ONE SIDE OF THE COIN: AN OVERVIEW OF ENVIRONMENTAL EQUITY}

The crux of the environmental equity (EE) argument is " . . . that poorer people in general, and people of color in particular, face risks-from their proximity to hazardous facilities and waste sites-that are disproportionate to their numbers in the population" (Williams, 1999, p. 313). Many authors place the origins of the EE movement in the early to mid 1980s (Williams, 1999; Worsham, 2000); others establish these a decade or more earlier (Weinberg, 1998). "Theorizing about environmental justice can be traced to work done in the 1970s. Even though it is rarely acknowledged, there was an influential group of political economists who documented important systematic features of global capitalism that distributed environmental externalities disproportionately to marginalized communities ([see] Schnaiberg, 1975; Anderson, 1976; Stretton, 1976; [and] . . . Buttell, 1987 for general review)" (Weinberg, 1998, p. 605).

The reason that the 1980s are generally cited as the period of EE nascency is because that's when things really began to pop, environmental justice-wise. In 1982, residents of Warren, a predominantly African-American county in North Carolina, protested the siting of a proximate polychlorinated biphenyl (PCB) landfill (Worsham, 2000). Five hundred people were arrested during the 1960s-civil-rightsstyle protests which attracted national attention and U.S. General Accounting Office (GAO) scrutiny (Bullard, 2000). Too, it was during this time that three major studies, often considered the very foundation of empirical EE literature (Bullard, 2000), reported correlative data to support the contention that communities with concentrations of poor and/or minority populations bore disproportionately higher numbers of locally undesirable land uses (LULU's) (e.g., chemical polluters, toxic waste sites, landfills). These studies were the GAO report on the proposed Warren, North Carolina PCB landfill, Siting Hazardous Waste Landfills and Their Correlation with Racial and Economic Status of Surrounding Communities, Professor Robert Bullard's study, Solid Waste Sites and the Houston Black Community, both 
published in 1983, and a 1987 research project commissioned by the United Church of Christ (UCC), Toxic Waste and Race in the United States (ibid.). These studies cleaved a chink in the floodgates holding back a reservoir of evidence purporting to substantiate environmental injustices, and soon research reporting correlations between race and/or poverty and environmental inequities began to pour through the breach-at first just a trickle, but soon a torrent. The literature would become voluminous (Williams, 1999). And, the public began to take notice. Worsham (2000) wrote:

The GAO and UCC findings received significant publicity and ... [i]n response to growing pressure from academics and government officials, President Bush's Environmental Protection Agency (EPA) Administrator William K. Reilly eventually established the "Environmental Equity" working group in 1990 to study environmental justice issues. WPA's 1992 Environmental Equity Report confirmed earlier studies, finding that members of minority populations have disproportionately greater observed and potential exposure to environmental pollutants, and this disproportionality could not be explained by income alone. [A] comparison between poor, African-American, and Hispanic percentages shows that these minority groups are more concentrated in [substandard air quality regions] than the poor population in general. (p. 635)

Proponents of environmental equity (e.g., Bullard, Jackson, the Congressional Black Caucus, the United Church of Christ Commission for Racial Justice) leveraged the notoriety of the North Carolina demonstrations, supporting academic literature and the highprofile reports published in the late 1980's to pressure those with political influence and the stamina to listen. As a result, the Federal Government swung ponderously into action. In 1990, the EPA created an internal environmental equity workgroup " ... to examine evidence regarding the inequitable distribution of environmental risk. The results of the workgroup's research convinced the EPA to create a new Office of Environmental Equity (now the Office of Environmental Justice)" (Ringquist \& Clark, 1999, p. 81). In June, 1992, the EPA released a report on environmental equity in which the agency stated "... evidence indicates that racial minority and low-income populations are disproportionately exposed to lead, selected air pollutants, hazardous waste facilities, contaminated fish tissue, and .. . [further that this exposure results in] . . . higher than average potential ... risks ... [suggesting that these populations are] . . more likely to actually experience harm due to these exposures" (USEPA, 1992, p. 1-2). In that same year, the United States Environmental Protection Agency established the EPA Office of Environmental Justice (OEJ).

According to Cooper (2001) still more force was applied, as pressures mounted:. . . to bring together the announced commitments to civil rights and to the environment that Clinton and Gore had echoed throughout the [1992] campaign. In hearings in March and April 1993, longtime civil rights advocate Don Edwards (DCA) took the lead in demanding that the EPA had an obligation under Title VI of the Civil Rights Act to move against recipients of federal funds who were engaged in environmental racism . . . That demand received vigorous support from the U.S. Commission on Civil Rights. In September, the Louisiana Advisory Committee (1993) published its hard-hitting report titled The Battle for Environmental Justice in Louisiana ... The report called on the [Civil Rights] commission to demand action. Chairman Arthur Fletcher obliged, writing to the EPA administrator and calling for the use of civil rights statutes and regulations to attack the problem. (p. 130)

Less than 6 months later, on February 11, 1994, President William Jefferson Clinton, signed what appeared to be a garden-variety (or should that be a Rose Garden-variety?; or as some would have it, sub rosa garden-variety?) presidential document, Executive Order (EO) 12898, to ensure "Environmental Justice in Minority Populations" (Clinton, 1994). Bob Bullard states, without compunction, that president Clinton authored this document "[i]n response to growing public concern and mounting scientific evidence . . ." (Bullard, 2000, p. 561). As we shall see in the next section, there are those who would disagree with Professor Bullard. 
Although many consider Executive Order 12898 to be the single most significant pronouncement for the political advancement of environmental justice (Bryant, 1995; Millan, 1998), the truth is that this document really did not do much (Cooper, 2001). In fact, in the final paragraph of that executive order, 6-609, Clinton states that in signing EO 12898, he intends only to improve the internal management of the executive branch (Clinton, 1994). A little later that same day, however, the president signed a second document, a somewhat less innocuous presidential memorandum on the same subject. This latter, minimally publicized and so less scrutinized, put the teeth in the preceding executive order. These two documents and their interpretation by the EPA provided the foundation and impetus (Bryant, 1995; Cooper, 2001; Liu, 2001; Whitehead \& Merritt, 1999) for a federal environmental justice juggernaut (Lester, Allen \& Hill, 2001). To some observers, the presidential promulgation of environmental equity was part of " . . a pattern of using presidential memoranda [and executive orders] to create and implement significant and often controversial policies throughout the [Clinton] administration" (Cooper, 2001, p. 127). Given the contentious nature of the environmental equity debate in both public forum and academic literature, it does not seem the least inappropriate that what many perceive as the seminal event (Millan, 1998) in the Federal Government's official campaign for environmental equity should begin in controversy.

Clinton, in the remainder of his second term as president, remained noticeably silent on environmental equity issues, " . . . and there has been no [further] executive leadership in this policy area" (Ringquist \& Clark, 1999, p. 80). As for federal agencies, administrations, departments and bureaus, well that's another matter. Environmental equity issues are currently very high on the EPA's list of priorities (Liu, 2001). The EPA Office of Civil Rights participates in the National Environmental Justice Advisory Council, an agency that exists to help local communities pursue remedies for environmental discrimination, and each EPA regional office now has an environmental justice coordinator to oversee efforts at improving environmental equity (Cooper, 2001).

The environmental equity movement picked up momentum throughout the decades of the 1980's and '90's to become a juggernaut. "[T]he growth of the environmental justice movement in the United States surprised even seasoned policymakers by its speed and the magnitude of its impact on national policy" (Lester, Allen, \& Hill., 2001, p. 1). However, even the silver lining of environmental equity is not without its dark cloud.

\section{THE OTHER SIDE OF THE COIN: AN ALTERNATIVE VIEW OF ENVIRONMENTAL EQUITY ISSUES}

In 1994, the same year that William Jefferson Clinton signed EO 12898, Vicki Been published Locally Undesirable Land Uses in Minority Neighborhoods: Disproportionate Siting or Market Dynamics? in the Yale Law Review, an article which refuted the validity of the claims made in the earlier environmental equity studies. Specifically, Been took exception with the causal relationships and strength of the correlations previously described (Been, 1994). Since this article was published, a debate has raged in the literature, which shows no sign of abating. According to Williams, "first wave" studies, of which the earliest were Professor Bullard's article and the GAO report, uncovered widespread inequities, but the body of later, "second wave" literature, starting with Been's piece, does not corroborate the findings of the first (Williams, 1999).

Among the "second wave" of researchers were those who agreed with Been that social dynamics may largely explain the appearance that poor and minority populations bear a disproportionate burden of environmental risks (Perhac, 2000; Sadd, Pastor, Boer, \& Snyder, 1999). "There is reason to believe . . . that disproportionality is not always, or even often, the result of environmental racism. Socioeconomic analyses, for instance, have revealed that in many cases minorities and the poor voluntarily move into higher-exposure neighborhoods, where property may be less expensive or jobs more plentiful ..." (Perhac, 2000, p. 91). Because some "researchers widely 
rely on . . . statistical data to identify areas of disproportional risk, without seeking out the underlying cause ... " (ibid, p. 92), the results of their research findings do not reflect the true nature of the phenomenon they are reporting.

The tendency in these instances has been to report a positive correlation for the existence of environmental inequity when, in fact, no injustice was perpetrated since the studied population chose with free volition to live in the high-risk area.

Others refer to this phenomenon (the movement into higher-risk neighborhoods of poor and minority populations under the influence of lower home ownership costs or higher paying jobs) as "minority move-in" (Sadd, Pastor, Boer, \& Snyder, 1999). The "second wave" authors have cogently argued that, to some greater or lesser extent (the exact impact is yet to be determined), "minority movein" explains the bias observed in the statistical correlation between the frequency of disadvantaged and minority individuals in proximity to hazardous sites and LULU's (Been, 1994; Perhac, 2000; Sadd et al., 1999). The "snapshot" approach to research practiced by the "first wave" of environmental equity researchers " . . . does not elucidate whether . . . [hazardous] facilities were located in minority areas or whether minorities moved in after the proximity to potential hazards shifted property values and neighborhood desirability" (Sadd et al., 1999, p. 119).

Other authors cite variations in spatial resolution (the size of the units selected as researchable areas) as an ongoing problem producing mixed results in the literature (Ringquist \& Clark, 1999; Steinberg, 2000; Worsham, 2000). For example, according to Williams (1999):

Among the various analyses of environmental injustice, we find different operationalizations of community. The several operational definitions conflict with one another, yielding divergent research conclusions. Earlier studies uncovered the national scope of environmental injustice for communities of color

Recent studies, however, have used different operational definitions, and have reached contrary conclusions about the scope of inequity. Some of the latter studies have not found evidence to support the claim that communities of color face disparate environmental inequities on a national scale. (p. 314)

Further, Williams cites a 1995 study wherein Glickman and Hersh purposely controlled the spatial resolution of the study area (Pittsburgh) to produce conflicting results with respect to environmental equity (1999). It appears that, just as setting the alpha level in a statistical study will affect statistical significance and reported outcomes, determining to what extent, if any, environmental inequities exist is greatly influenced by the research design, particularly the spatial resolution chosen for study. (This phenomenon is sometimes referred to as geographic scale effect or just scale effect.) The choice of using political jurisdiction, community, neighborhood, zip code or census tract as the unit of analysis must be carefully evaluated before beginning any environmental equity research, as outcome and validity hang in the balance. Willia ms concludes his 1999 article by pointing out that the injudicious use of spatial resolution has inflamed the environmental equity debate.

\section{SOME RELEVANT COMMENTS FOR PERSPECTIVE}

The above cited uncertainties and controversies notwithstanding, several points are apposite to this discourse: 1) Environmental equity issues are a reality to be dealt with in the foreseeable future (Millan, 1998; Steingberg, 2000; Worsham, 2000). 2) With or without strong scientific evidence supporting claims of environmental racism or injustice, the Federal Government and Federal Courts will shape and control the evolution of the meaning and impacts of environmental equity (Whitehead \& Merritt, 1999; Worsham, 2000). 3) It is not unlikely that we will observe " . . a an explosion of regulatory and judicial activity in site permitting and renewals" (Whitehead \& Merritt, 1999, p. 33). 4) Due to the significance and volatility of this issue, both immediate and potential, stakeholders, regardless of affiliation or motivation, must receive the highest quality information obtainable (Worsham, 2000). 
Increasingly, those who research environmental equity issues are beginning to question the extent, or even the existence, of disproportionality in the spatial distribution of hazardous facilities or locally undesirable land uses (LULU's) proximate to minority and poor populations. In dispute are: 1) the causes of these inequities (e.g. if these are the result of socio-economic dynamics, then the resident population freely chose to live in the affected area and hence factors other than discrimination are responsible); 2) the extent of such inequities, where they may exist; 3) the degree to which any discriminatory injustice may have been done. Many authors (previously cited) believe that much of the existing environmental justice literature (and, therefore, the beliefs and policies engendered by corresponding research) are based on imprecise or flawed methodologies. In the following analysis, the authors of this paper examine how the use of various research strategies can influence environmental justice analyses to the extent of confounding research outcomes, or worse, provide a means for manipulation of the experiment to foreordain the resultant findings.

\section{MODELING NOISE IMPACTS IN AREAS SURROUNDING LAMBERT-ST. LOUIS INTERNATIONAL AIRPORT}

\section{GENERATING THE NOISE CONTOURS}

The use of geographic information systems (GIS) has emerged as an applied research strategy applicable to the analysis of the spatial aspects inherent in environmental justice studies (Liu, 2001; Perhac, 2000; Sadd et al., 1999) as well as transportation issues (Chakraborty, Schweitzer, \& Forkenbrock, 1999; Forkenbrock \& Schweitzer, 1999). As an applied research tool, GIS is particularly suited to exploring the impacts of airport noise on protected populations. In an analysis similar to that recommended by the FAA for EIS studies and, therefore, used in previous EE researches examining transportation engendered externalities (Chakraborty, Schweitzer, \& Forkenbrock, 1999; Most, Sengupta \& Burgener, 2002), the authors of this paper relied substantially on the spatial capabilities of GIS, using Environmental Systems Research Institute's (ESRI's) ArcView 3.2 and ArcGIS 8.0 (as well as the Integrated Noise Model (INM), version 3.0c) to evaluate the dynamics of the population demographic, race, over a period interimistic to the census years, 1990 and 2000. In performing the analysis, the authors generated a series of noise contours for 1990 and 2000 based on data obtained from the FAA (USDOT, FAA 1990; USDOT, FAA 2000) and Bureau of Transportation Statistics (BTS) (USDOT, BTS, 2002). The INM, developed under the auspices of the Federal Aviation Administration, was used to evaluate aircraft noise impacts on neighborhoods around Lambert-St. Louis International Airport. Runway usage, specific aircraft and powerplant types, flight operations and flight path information, obtained from the most recent Lambert Environmental Impact Statement (USDOT, FAA, 1997), were analyzed and coded for nput into the INM. Integrated Noise Model defaults produced the most conservative surrogate flight profiles. The INM generated noise contours in 5 decibel $(\mathrm{dB})$ increments using an "A-weighted" measure, which is derived by electronic filtering or mathematical transformation of actual measured decibels to approximate sensitivity of the human ear to various levels and frequencies of sound. Further adjustment of the noise levels experienced by the affected population is achieved by the use of Day-night Average Sound Level (DNL), which more heavily weights night operations.

The Federal Interagency Committee on Noise (FICON) suggests a $60 \mathrm{~dB}$ DNL as the baseline for airport noise contours for two reasons: (1) "The ability to determine the contribution of different noise sources is ... diminished at lower noise levels. At lower DNL values, the existing non-aircraft noise may mask the aircraft noise. In the airport environs, the non-aircraft noise may begin to dominate aircraft noise at levels below DNL $60 \mathrm{~dB}$ " (FICON, 1992, p. 3-5). (2) "[B]ecause public health and welfare effects below DNL $60 \mathrm{~dB}$ have not been well established, the FICON decided not to recommend evaluation of aviation noise impacts below DNL $60 \mathrm{~dB}$ " (USDOT, FAA, 2000, p. 43809). 
Using the INM, the authors initially generated contours in increments of $5 \mathrm{dBA}$ for the census years 1990 and 2000, producing eight areas having modeled exposures of $60-65 \mathrm{~dB}, 65-$ $70 \mathrm{~dB}, 70-75 \mathrm{~dB}$, and $75-80 \mathrm{~dB}$ levels of $\mathrm{A}-$ weighted, DNL noise. Because the $75 \mathrm{~dB}$ contour generally fell along, or just outside the airport boundary it was retained, and three areas of analysis (falling within the boundaries of the $60-65 \mathrm{~dB}, 65-70 \mathrm{~dB}$, and $70-75 \mathrm{~dB}$ contours) were generated for each census year. In this way, two sets of three contours were created, producing a total of six areas of interest. These decadal contour pairs (e.g., the $65-70 \mathrm{~dB}$ contours for 1990 and 2000 represent one decadal contour pair) were next combined into composites to delineate the boundaries of those areas assumed to be consistently exposed to the corresponding levels of noise over the 10 year period under consideration. We thus produced three composite contours of $60-65 \mathrm{~dB}, 65-70 \mathrm{~dB}$, and 70-75dB (See Figure 1, Appendix A). Each was smaller than either pair from which it was generated, as these composites represented only those areas likely to have received the corresponding level of noise during the decade spanning the period between 1990 and 2000.

For reasons discussed below, the $65-70 \mathrm{~dB}$ area was subsequently discarded, leaving two areas of analysis: those within the composite $60-65 \mathrm{~dB}$ and $70-75 \mathrm{~dB}$ contours.

The authors output the INM contours in a CAD ".dxf" format, saving these for subsequent input into the GIS software. Using ArcView, each ".dxf" contour pair was converted to a shapefile and re-projected to UTM NAD 83/Zone 15. We next created, with ArcINFO/ArcGIS 8.0, coverage polygons having topology attributes. (This enhancing operation was necessary to provide the ability to later "clip" census blockgroups with the composite contours.) Census blockgroups in ArcInfo ".e00 file" format were obtained from Missouri Spatial Data Information Service and Census Bureau databases (MSDIS/US Census Bureau 2001) for St. Louis County, St. Louis City, and St. Charles County and converted to shapefiles. Using ArcView, the authors merged the blockgroup shapefiles, clipping these with the enhanced contour polygons (See Figure 2, Appendix A). To explore the potentially confounding influences of various analytical techniques, two reference population aggregations and four spatial scale strategies were employed in analyses, which produced the demographic totals from which descriptive statistics were computed.

\section{DETERMINING THE REFERENCE POPULATION}

Our analysis next required a frame of reference, a comparison population against which to judge the impacts of modeled outcomes on protected groups. In reality, no clear guidance is available, and the selection of the reference population is often arbitrary. Consider the advice offered by the FAA and the Council on Environmental Quality (CEQ) - the agency designated to ensure compliance with the National Environmental Protection Act (NEPA) and the president's chief environmental advisory group. Once the minority population has been defined, " . . . care should be taken to determine if the percentage of minority population within the affected area is 'meaningfully greater' than the minority population's percentage in the general population or other 'appropriate unit of geographic analysis"” (FAA 2000, p. 6). The CEQ sets the criteria for this determination at $50 \%$ minority population or a minority population percentage present in the affected area "meaningfully greater" than the minority population percentage present in the general population or other appropriate unit of geographic analysis. Unfortunately, the definitions of "meaningfully greater" and "appropriate unit of geographic analysis" are nowhere given. Finally, CEQ guidance stipulates that "[i]f environmental justice concerns exist, the potential impacts to this population from the proposed action must be assessed" (ibid.). As previously mentioned, this lack of guiding specificity in determining the reference population has been cited by several authors as being responsible for conflicting and confounded research outcomes existing in $\mathrm{EE}$ literature.

In this analysis, the reference group could be selected in one of two ways. Because the original noise contours lie across parts of three large census units (St. Louis County, St. 
Charles County and the metropolitan area of St. Louis, Missouri), the individuals residing in these areas might be aggregated to produce a reference population. A second approach would be based on the fact that intact blockgroups are located in either St. Louis County or the city of St. Louis (the census unit west of the Mississippi River). Table 1 in Appendix B summarizes these two approaches, wherein subtotal values are associated with the latter option (the sum of St. Louis city and county values) and grand total numbers are derived from the former (the aggregated population figures from all three census areas).

\section{CONFOUNDING EFFECTS OF RESEARCH STRATEGIES}

\section{IDENTIFYING THE UNITS OF ANALYSIS}

High-resolution spatial data are desirable, but often not available, and selection of a particular geographic unit (e.g., census blocks over blockgroups, or tracts in lieu of zip codes) may be necessitated by the availability of data or the type of study being conducted. For example, in some types of studies (e.g., longitudinal analysis of data from a period spanning several decades) the use of coarser data may be attractive because areas having greater spatial extent are more stable with respect to time. Such exigencies notwithstanding, the spatial resolution of the area must be chosen with care to prevent negating research outcome validity. In this study, various census areas were considered and subsequently rejected. Zip codes and census tracts were too large, since more than one contour cut across the same area. When aggregated in this way, the data became too coarse for analysis. On the other hand, not all relevant data necessary to complete the analysis were available at the block level. Consequently, the authors selected blockgroups as the census units upon which this particular analysis would be based.

\section{THE ANALYSES}

\footnotetext{
"Within analysis," "adjacency analysis," "cross-area transformation" and "areal interpolation" represent four methods available
}

to environmental equity researchers for use in determining the area impacted by an externality (in this case, the noise associated with operations at Lambert-St. Louis). Each strategy is simple and straightforward, providing an uncomplicated way to characterize the area of analysis. "Within analysis" allows the use of only those geographic units contained entirely within delineating boundaries. In the context of our analysis, only those blockgroups surrounding the airport and completely within the composite noise contours were considered for the within analysis. The use of such discrete geographic units is a simple method ensuring that the entire population of that area has been equally exposed to a given externality. One danger in such an approach is that the characteristics of such a small, isolated sample may not be representative of the greater population purported to experience the undesirable impacts. Another problem in the use of a "within analysis" strategy is the exclusion of those geographic units not wholly bounded by the area of study. For example, in our analysis the use of blockgroups necessitated discarding the composite 65-70 dBA contour, because no blockgroup fell completely within its boundaries. The within analysis was performed for a total of six blockgroups: two fell between the 70-75dB composite boundaries and four were inside the those of the $60-65 \mathrm{~dB}$ contour (Fig. 2). The results are provided in Appendix B, Table 2

In an attempt to overcome what is known as "border effect," environmental equity researchers may employ the strategy of "adjacency analy sis" (Liu, 2000). When a study is too narrowly constrained to the boundaries of the geographic unit(s) containing or adjoining the source of the externality while other areas actually experiencing environmental impact(s) are not considered, border effect produces results that do not accurately characterize the attributes under investigation. The confounding effects of areal units too narrowly defined on research outcomes may be the result of an inadequate understanding of the phenomenon under investigation or, the more egregious circumstance, a desire for expediency.

Using ArcView, the authors identified

all blockgroups contained partially or 
completely within the $60-65 \mathrm{~dB}$ and $70-75 \mathrm{~dB}$ composite contours. The blockgroups thus identified became the basis for performing the "adjacency analysis", which yielded a total of 141 blockgroups. Of these, 101 were intersected or contained by the $60-65 \mathrm{~dB}$ contours and 40 were within or contiguous to those associated with the 70-75dB levels. Aggregated "adjacency analysis" blockgroup values for the composite contours were calculated; the results are summarized in Table 3, Appendix B. Where the researcher suspects that "within or adjacency analysis" may produce unrealistic results or confound research outcomes, spatial interpolation techniques (discussed below) may be appropriate alternatives.

Spatial interpolation techniques may be employed to overcome the limitations of partial geographic areas, such as those created by certain GIS operations (e.g., buffering and clipping). Because truncated blockgroups represent only a fraction of the entire geographic unit of analysis, researchers may ascribe characteristics to the impacted region through the process of spatial interpolation, a form of mathematical transformation. Two interpolation methodologies applicable to environmental equity studies are areal interpolation and crossarea transformation. The mathematical formula for areal interpolation is frequently given as (Chakraborty \& Armstrong, 1996; Liu, 2000; Margai, 2001):

$$
P=\sum_{i=0}^{n} P_{i}+\sum_{j=0}^{m}\left[P_{j}\left(\frac{A_{j e}}{A_{j}}\right)\right]
$$

Where:

$$
\begin{aligned}
& \mathrm{P}=\text { total population inferred through the } \\
& \text { interpolation process. } \\
& \mathrm{n}=\text { number of geographic units (e.g., } \\
& \text { blockgroups or census tracts) } \\
& \text { contained entirely within the } \\
& \text { delimiting boundary. } \\
& \mathrm{P}_{i}=\text { population of the intact geographic } \\
& \text { unit, } \mathrm{n} . \\
& \mathrm{m}=\text { those partial geographic units (as } \\
& \text { might be truncated by a GIS } \\
& \text { operation). }
\end{aligned}
$$

$\mathrm{P}_{j}=$ population corresponding to the partial geographic unit, $\mathrm{m}$.

$\mathrm{A}_{j e}=$ the partial area of the truncated geographic unit.

$\mathrm{A}_{j}=$ the total area of the truncated geographic unit.

The above formula allocates population numbers to all areas created by a GIS clip, intersection or buffer operation by assigning values to each geographic unit based on the proportion of the areal region created by the GIS truncation as compared to the total area of the complete feature. (As example: If a blockgroup is clipped so that $25 \%$ of its area remains inside the perimeter of the GIS-generated polygon and the total population of the original unit was $8,000,50 \%$ of which met the criteria of being minority under federal guidelines, then it is assumed that 1,000 protected persons would reside within the area created by the clipping operation.) To derive the total population of the area of analysis, the inferred values for all partial areas created by GIS operations are summed and added to those of the units falling completely within the boundaries of the clipped or intersected extent. Applying this strategy to the $60-65 \mathrm{~dB}$ and $70-75 \mathrm{~dB}$ contour areas produced the values given in Appendix B, Table 4.

Researchers may use cross-area transformation to ascribe unknown demographic characteristics to an area of analysis. This form of interpolation may be defined as a technique capable of generating attribute data based on one type of zone (the source zone) and subsequently assigning the inferred values to another (the target zone). It is a hybrid methodology, related to both areal interpolation and "within analysis." Because values are assigned following certain GIS operations to incomplete geographies based on the percentage of extant areas, cross-area transformation is akin to areal interpolation. It is related to "within analysis" in the sense that the area to be analyzed is generated based on the same intact geographic units completely contained within the boundaries of the delineating feature-these are the source zones. A percentage of the source zone population is assigned to the partial geographies according to the percentage of target zone remaining in the area of analysis subsequent to a GIS operation such as clipping, intersecting or buffering. The 
justification for such assignment is the assumption that any geographic unit completely contained within the area of analysis will accurately (or at least adequately) represent the demographics of the population residing within the larger area. The mathematical formula for cross-area transformation may be given as (Most et al., 2002):

$$
P=\sum_{i=0}^{n} P_{i}+\sum_{j=0}^{m}\left[P_{i x}\left(\frac{A_{j e}}{A_{j}}\right)\right]
$$

where the symbols and variables are the same as those of the areal interpolation formula, with the exception that $P_{i}{ }_{x}$ represents the source zone from which target zone values are inferred.

For this analysis, the authors identified blockgroups completely contained within the composite INM contours as the source zones. These blockgroups are the base features from which population characteristics for the target zones - the extant portions of the blockgroups truncated by the GIS clipping operation-may be developed by multiplying the demographic values of an appropriate source zone by the proportion of each partial blockgroup intersected by the $60-65 \mathrm{~dB}$ and $70-75 \mathrm{~dB}$ contours. Summing source and target zone values generated the results presented below in Table 5, Appendix B.

\section{RESULTS OF THE ANALYSES}

Given the values in Table 1 , the proportion of the population identified as belonging to protected groups (i.e., minority or non-white) remained essentially constant in the combined St. Louis City/County reference area during the ten year period under consideration: In 1990, individuals identified under census guidelines as being protected against environmental injustices accounted for $33.16 \%$ of the total population; in 2000 this value was $33.33 \%$. When conflating these figures with those of St. Charles County, the numbers change somewhat, with $22.42 \%$ of the population being protected in 1990 as compared to $27.06 \%$ in 2000. This $4.64 \%$ increase in the proportion of protected populations in the aggregated census area is attributable to the increase in minority populations (from $15.83 \%$ to $23.17 \%$ ) in St. Charles County.

When using the values obtained from the "within analysis" (Table 2), 97.51\% of those living within the 60-65dB contour in 1990 belonged to protected populations; this percentage had increased to $98.17 \%$ by 2000 . Such an increase, consistent with much of the research cited in environmental justice literature, would be expected if airport noise reduced property values to act as attractor inducing minorities and lower income families to populate the area. Further, the finding of such a large percentage of the population belonging to groups considered "protected" would certainly be considered aberrant and fit the strictest interpretation of the CEQ's criteria of "meaningfully greater" in comparison to either reference population.

However, the population values for the $70-75 \mathrm{~dB}$ contour are not expected: only $20.26 \%$ of the 1990 population was considered protected; in 2000, this figure was $29.41 \%$. These values are approximately equal to, or less than, those of the general population, depending on which reference population is used (Table 1). In fact, the argument could be made when using the St. Louis City/County values for comparison, that those belonging to the unprotected, non-minority population are bearing a disproportionate share of the impact of environmental inequity. The fact that a significantly lower percentage of the protected population resides in the area of more highly elevated levels of noise makes the results of the "within analysis" all the more surprising.

The cross-area transformation (Table 5) also produced mixed results. This is not unexpected, considering the unit upon which the interpolation equation calculates target zone values is taken from the within analysis set. For groups considered protected and residing within the $60-65 \mathrm{~dB}$ contour, the cross-area transformation equation assigned a value of $95.53 \%$ and $98.77 \%$ to the 1990 and 2000 target zones, respectively. For the $70-75 \mathrm{~dB}$ contour, the values were $52.68 \%(1990)$ and $62.01 \%$ (2000). The expected increase in the percentages of minorities in the noise contour target zones over the ten-year period is again 
evident, as is the seemingly contradictory finding of fewer protected individuals in the higher noise areas. When compared to the totals obtained in the areal interpolation, those of the cross-area transformation were much lower, reflecting the influence of the arbitrarily selected source zone. In comparison to the general population, the higher percentages in both the $60-65 \mathrm{~dB}$ and $70-75 \mathrm{~dB}$ areas would likely be considered excessive under the CEQ guideline of "meaningfully greater."

In comparison to the results of the "within analysis" and the cross-area transformation, those obtained using areal interpolation differed markedly, at least in terms of percentages. In the $60-65 \mathrm{~dB}$ contour, the non-protected population declined from $59.15 \%$ in 1990 to $48.91 \%$ in 2000 , while protected populations increased from $40.85 \%$ to $51.09 \%$. The protected population totals in the area defined by the $70-75 \mathrm{~dB}$ composite were again lower in the higher noise area, although the percentage increased from $34.21 \%$ to $48.25 \%$.

With respect to changes in the minority population over time, the adjacency analysis (Table 3) produced more consistent outcomes, varying by no more that $0.3 \%$ from one census year to the other. These results differ considerably from those obtained with previous methodologies. The 1990 values for protected populations were $31.68 \%$ and $31.65 \%$ for the $60-65 \mathrm{~dB}$ and $70-75 \mathrm{~dB}$ contours, respectively; given in the same relative order, those for the year 2000 were $43.62 \%$ and $43.39 \%$. The relative stability in population figures across areas having significantly different levels of noise is contradictory to the expectation that the more significant externality apparent in the 70$75 \mathrm{~dB}$ contour would reduce property values, inducing poorer and minority populations to occupy the area in higher densities.

Note that the values for the $60-65 \mathrm{~dB}$ contour for both the "adjacency analysis" and areal interpolation (Table 4) are considerably less than those obtained using the "within analysis" and cross-area transformation. Notice too, that whether the lower values in the 70$75 \mathrm{~dB}$ target zones of the "adjacency and within analyses" are statistically significant could well depend on the type of statistic used, the alpha level of the statistical test, and whether one elected to use the St. Louis City/County or conflated St. Charles/St. Louis reference population as the independent or predictor variable. The commonality among all the analyses is the increase in the percentage of minorities in all populations. However, because this trend is also apparent in the reference population, the question then becomes whether the rate of increase is greater in areas exposed to higher levels of noise than in those where the level falls below 60dB. Most relevant to this discourse are the disparate results produced by the various analytical methodologies.

\section{CONCLUDING COMMENTS}

It is clear from comparison of the foregoing analyses that, to obtain valid results, extreme care must be exercised not only in the selection of the tools and strategies of the research design, but also in the interpretation of the outcomes. This is crucial where the use of powerful computers, sophisticated GIS software, and elegant statistical analyses lend an aura of authority and authenticity to the most flawed of investigations. The outcomes of environmental justice investigations, and, consequently, the conclusions based on the results of such studies, are critically dependent upon the analytical strategy to be applied in deriving statistical outcomes and the spatial resolution of the research design as dictated by the researcher's choice of reference unit. With this in mind, consider that the selection of both research methodology and unit of analysis is subjective and ". . . often dictated by expediency, determined by how existing data bases are aggregated and which level of aggregation provides the most data at the smallest geographic scale" (Zimmerman, 1993, p. 652, quoted in Liu, 2000, p. 138). The arbitrary, perhaps cavalier, selection of areal reference units and research strategies imbue environmental justice research with a certain vulnerability.

For example, recall how one outcome obtained using the "within analysis," would tend to support the argument that those belonging to the population not protected under the aegis of federal regulations are bearing a disproportionate share of the noise externality 
attributable to Lambert-St Louis International Airport. This conclusion is dependent upon choice of reference population used for comparison to those groups considered protected. Recall, too, how completely arbitrary is the selection of the cross-area transformation reference unit, $\left(P_{i x}\right)$, upon which the assignment of target zone population demographics rests. By selecting one or another reference unit having uncharacteristic, perhaps even "outlier" attributes, an investigator may foreordain the outcome of the interpolation. Carelessness in selecting $P_{i x}$ values may cause the researcher to inadvertently choose an inappropriate reference unit, thus confounding the findings. Worse, an unscrupulous investigator (e.g., one having "an axe to grind") can easily manipulate data through the a priori selection of a biased estimator. The verity of research analyses that focus on population demographics in the context of environmental equity is completely dependent on the careful and judicious selection of research tools and strategies. Perhaps more so than in other research endeavors, where attempting to assess the impacts of environmental externalities on a given population, the application of logic and reason to the selection of appropriate methodologies and the analysis of outcomes is essential in reaching valid conclusions.

That environmental equity researches are vulnerable to confounding biases is of what significance to those involved in aviation, or, for that matter, any other segment of the transportation industry? Largely due to implementation of EO12898, as outlined in the introduction to this paper, agencies, administrations and bureaus at all levels of the government mandate environmental justice analyses as part of the Environmental Assessment and Environmental Impact Statement processes. The requirement for such analyses slows efforts to lengthen runways, build new airports and expand existing ones. Where the outcomes of such analyses are challenged in court, the litigation/adjudication processes have the potential to significantly slow transportation capacity enhancements. Court battles over the EIS process are also expensive, consuming tax dollars and increasing the cost of infrastructure construction-costs that are ultimately transferred to the consumers of transportation services. Where based on biased research outcomes, such legal challenges have no validity. Even where the goal is noble, as in the championing of indigent or minority populations, the use of flawed data and confounded research outcomes to support opposition to capacity enhancements is an abrogation of the responsibility to provide an accurate accounting of the facts. Even here, the ends do not justify the means. 


\section{REFERENCES}

Alonso-Zaldivar, R. (2001, February 3). U.S. backs new jet runways to ease delays. Los Angeles Times. Retrieved February 3, 2001 from latimes.com http://www.latimes.com/print/asection/20010201/ t000009526.html.

Been, Vicki. (1994). Locally undesirable land uses in minority neighborhoods: disproportionate siting or market dynamics? Yale Law Journal 103, 1383-1422.

Bryant, B. (1995). Environmental justice: issues, policies and solutions. Washington, DC: Island Press.

Bullard, R. D. \& Johnson, G.S. (2000, Fall) Environmental justice: grass roots activism and its impact on public policy decision making. Journal of Social Issues, 56(3), 555-578.

Chakraborty, J., Schweitzer, L. A. \& Forkenbrock, D. J. (1999). Using GIS to assess the environmental justice consequences of transportation system changes. Transactions in GIS 3(3), 239-258.

Clinton, W. J. (1994, May). Federal actions to address environmental justice in minority populations and low-income populations. Reprint of executive order no. 12898 (February 11, 1994). Environment 36(4), 16-19.

Cooper, P. J. (2001, March). The law: presidential memoranda and executive orders: of patchwork quilts, trump cards, and shell games. Presidential Studies Quarterly, 31(1), 126-141.

Federal Interagency Committee on Noise (FICON). (1992, August) Federal agency review of selected airport noise analysis issues volume 1. Policy Report. Washington, DC.

Forkenbrock, D. J. \& Schweitzer L. A. (1999, Winter). Environmental justice in transportation planning. Journal of the American Planning Association, 65(1), 96-111.

Lester, J. P., Allen D. W. \& Hill, K. M. (2001). Environmental injustice in the united states: myths and realities. Boulder, Colorado: Westview Press.

Liu, F. (2001) Environmental justice analysis. Boca Raton, Florida: Lewis Publishers.

Margai, F. L. (2001, August). Health risks and environmental inequity: a geographical analysis of accidental releases of hazardous materials. Professional Geographer, 53(3), 422-434.

McNerney, M. T. (1995). The use of geographical information systems for airport engineering and management. Aviation Research Center Report Number ARC-700. Austin: University of Texas Center for Transportation Research.

Millan, S. (1998, Summer) And environmental justice for all. Journal of Environmental Law and Practice, 6(1), 58-63.

Most, M. T., Sengupta, R. \& Burgener, M. A. (2002). Spatial scale and population assignment choices in environmental justice analyses. Manuscript submitted for publication.

Ott, J. (2001, February 12). Runway advocates seek to ease regulatory bind. Aviation Week and Space Technology, 154(7), 32-34. 
Pellow, D. N. (2000, January). Environmental inequality formation: toward a theory of environmental justice. The American Behavioral Scientist, 43(4), 581-601.

Perhac, R. (2000, Fall). Environmental quagmire. Forum for applied Research and Public Policy, 15(3), 90-94.

Ringquist, E. J. \& Clark, D.H. (1999, Spring) Local risks, states' rights, and federal mandates: remedying environmental inequities in the u.s. federal system. Publius, 29(2), 73-93.

Sadd, J. L., Pastor M. Jr., Boer, J. T. \& Snyder L.D. (1999, May). 'Every breath you take . . '’: the demographics of toxic air releases in southern California. Economic Development Quarterly 13(2), 107-123.

Salant, J. D. (2001, April 26). Airlines schedule too many flights. The Washington Post. Retrieved April 27 from washingtonpost.com, wysiwyg:/8/http://washingtompost.com/wp-dyn/articles/A38042001Apr26.html.

Steinberg, M. W. (2000, Fall). Making sense of environmental justice. Forum for Applied Research and Public Policy, 15(3), 82-89.

Torriero, E. A. \& Zajac A. (2001, June 11) Runways face built-in delays. Chicago Tribune. Retrieved June 12, 2001, from chicagotribune.com, wysiwyg:/4/http://chicago tribune.com...ion/ariticle/0,2669,SAV-0106110161,FF.html.

United States Census Bureau. (2001, June 27). Summary file 1, standard extract, census 2000. American Fact Finder. Retrieved February 16, 2002, from http://factfinder.census.gov/ servlet/ProductBrowserServlet?id=101769\&product=Census\%202000\%20Summary\%20File\%201 Missouri\%20\%28FTP\%20Version\%29\&_lang=en.

United States Department of Transportation (USDOT). (1997, April 15). Department of Transportation (DOT) Order to address environmental justice in minority populations and low-income populations. Federal Register 62(72), 18377-18381.

United States Department of Transportation, Bureau of Transportation Statistics (USDOT, BTS), (2000) Airline on-time statistics: detailed statistics. Airline Information. Retrieved March 22, 2002 from http://www.bts.gov/ntda/oai/DetailedStatistics/.

United States Department of Transportation, Federal Aviation Administration. (1990). Table 7-aircraft departures scheduled and aircraft departures performed, by community, by air carrier, and by aircraft type 12 months ended December 31, 1990. Airport Activity Statistics of Certificated Route Air Carriers. Washington, D.C.: U.S. Government Printing Office.

United States Department of Transportation, Federal Aviation Administration (USDOT, FAA). (1997). Lambert-st. louis international airport final environmental impact statement. Kansas City, Missouri: Midwest Region.

United States Department of Transportation, Federal Aviation Administration. (2000, July 14). Aviation noise abatement policy 2000. Federal Register 65(136), 43802-43824. 